\title{
CENTRO DE MATERIAL E ESTERILIZAÇÃO: PADRÕES ARQUITETÔNICOS E O PROCESSAMENTO DE ARTIGOS
}

\author{
CENTRAL SUPPLY SERVICE DEPARTMENT: ARCHITECTONIC PATTERNS AND THE INSTRUMMENTAL \\ PROCESSING

\section{CENTRO DE MATERIAL Y ESTERILIZACIÓN: ESTÁNDARDES ARQUITECTÓNICOS Y EL PROCESSAMENTO DE MATERIALES}

\section{Simone Vieira Toledo Guadagnin¹, Mariusa Gomes Borges Primo², Anaclara Ferreira Veiga Tipple², Adenícía Custódio Silva Souza ${ }^{3}$}

RESUMO: O Centro de Material e Esterilização (CME) destina-se a receber e lidar com materiais considerados sujos e contaminados, e ao final do processo restituí-los esterilizados (BRASIL, 1994). O Ministério da Saúde (BRASIL, 2002), em relação à planta física recomenda um fluxo contínuo sem retrocesso e sem cruzamento do material limpo com o contaminado. Os objetivos deste estudo foram: identificar os padrões arquitetônicos dos CME dos hospitais de grande e médio porte da cidade de Goiânia e analisar a relação destes padrões com o processamento de artigos. O estudo foi realizado em todos os hospitais de grande e médio porte da cidade de Goiânia, após aprovação por um comitê de ética e consentimento livre das instituições. O estudo foi realizado em 23 hospitais, os dados foram obtidos por meio de cheeck list, após validação e teste, e analisados no programa Epi-Info 6.04. O estudo revelou que $78,3 \%$ das instituições possuem CME vinculadas ao Centro Cirúrgico, que 91,3\% não possuem áreas específicas, para cada etapa do processamento dos artigos, e ainda a falta de barreira física entre as áreas suja e limpa e ausência de vestiário para os trabalhadores, evidenciando a comunicação entre áreas com diferentes níveis de contaminação. Há predominância de portas de madeira $69,6 \%$ que são contra indicadas por conter frestas e saliências, $17,4 \%$ dos CME não possuem ralos em todas as áreas e 34,8\% não possuem ralos no expurgo. Em 91,3\% não existem lavatórios específicos para as mãos. O estudo evidenciou o descumprimento de normas estabelecidas pelo Ministério da Saúde para a estrutura física do CME que pode exercer influência como dificultadora ao processamento de artigos nos hospitais que fizeram parte do estudo e consequentemente, ao controle de infecção nestas Instituições considerando-se ser a esterilização a principal medida de proteção antiinfecciosa.

PALAVRAS-CHAVE: Arquitetura; Esterilização; Infecção Hospitalar.

SUMMARY: The Central Supply Service Department (CSSD) is bound of getting and dealing with materials known as filthy and contaminated, in order to make them sterilized in the end of the process (BRASIL, 1994). The Ministry of Health (2002) focusing on the building draft recommends a continuous flow without retroceding or even the contact between filthy and clean materials. The main goals of this research were: identify the CSSD architectonic patterns of largest hospitals in Goiânia along with analyze the relation of this patters with the material processing. This research covered the biggest and the average-sized Hospitals in Goiânia, after free consentient of the institutions and ethic committee approval. The research were made in 23 Hospitals, and all data were taken through the check list, after the test approval, and analyzed through Epi-info 60.4 program. The researched highlighted that $78.3 \%$ of the institutions have got CSSD linked to the Surgery Center, $97.3 \%$ have no specific areas to deal with each step of the articles processing, not to mention the relation among areas of different contamination levels. Besides $69 \%$ of the doors are made of wood which are not indicated due to cracks and saliences, $17.4 \%$ of CSSD do not have gratings in all areas and $34.8 \%$ do not have cleanse grating. $91.3 \%$ have no sink specifically for hand washing, This research clearly showed the disrespect to the Ministry of Health rules over physical structure of CSSD which can influence badly the articles processing in Hospitals, to the infections control in this institutions considering sterilizations the main policy against infection

KEY WORDS: Architecture; Sterilization; Infection Control.

RESUMEN: El Centro de Material y Esterilización (CME) está destinado a recibir y lidar con materiales considerados sucios y contaminados, y al final del

${ }^{1}$ Enfermeira do Hospital das Clínicas da Universidade Federal de Goiás. Aluna do Programa de Pós-Graduação Mestrado em Enfermagem da Faculdade de Enfermagem da Universidade Federal de Goiás. Goiânia, GO. E-mail: guadagninsimone@hotmail.com

2 Enfermeira do Hospital das Clínicas da Universidade Federal de Goiás. Aluna do Programa de Mestrado em Epidemiologia do Instituto de Patologia Tropical e Saúde Publica da UFG.

3 Enfermeira. Doutora em Enfermagem. Professora Adjunto da Faculdade de Enfermagem da Universidade Federal de Goiás. Goiania, GO. E-mail: anaclara@fen.ufg.br. 
GUADAGNIN, Simone Vieria Toledo; PRIMO, Mariusa Gomes Borges; TIPPLE, Anaclara Ferreira Veiga; SOUZA, Adenícia Custódio Silva. CENTRO DE MATERIAL E ESTERILIZAÇÃO: PADRÕES E O PROCESSAMENTO DE ARTIGOS. Revista Eletrônica de Enfermagem, v. 07, n. 03, p. 285 - 293, 2005. Disponível em http://www.fen.ufg.br/Revista/revista7 3/original 05.htm

proceso restituirlos esterilizados (BRASIL. MS, 1994). El Ministerio de Salude (2002), en relación a la planta física recomenda un flujo continuo sin retroceso y sin cruzamento del material limpo con el contaminado. Los objetivos de este estúdio han sido: identificar los estándars arquitectónicos de los CME de los hospitales de grandes y medianos de la ciudad de Goiânia y analizar la relación de estos estándars con el procesamiento de artículos. El estúdio ha sido relizado en todos los hospitales de grandes y medianos de la ciudad de Goiania, después de la aprobación por un comité de ética y consentimento libre de lãs instituciones. El estúdio ha sido realizado en 23 hospitales, los datos han sido obtenidos por médio de check list,después de una convalidación y prueba, y analizados en el programa Epi Info 6.04. El estúdio ha revelado que $78,3 \%$ de lãs instituciones possen CME vinculadas al Centro Cirúrgico, que 91,3\% no possen áreas específicas, para cada etapa del procesamiento de los artículos, y además la falta de división física entre lãs áreas súcia y limpa y

\section{INTRODUÇÃo}

A infecção hospitalar apresenta-se como um agravo de grande significado epidemiológico dentro do contexto da assistência hospitalar. Na busca de meios para sua prevenção e controle, certa parcela de responsabilidade cabe ao planejamento preditivo dos hospitais. Visa, no âmbito da segurança, dotar os projetos arquitetônicos e de engenharia, ainda na fase de elaboração, de barreiras, proteções, meios e recursos físicos, funcionais e operacionais. O assunto é de extrema relevância e vem sendo discutido em cursos, congressos e publicações, ao mesmo tempo, tem recebido contribuições de institutos de pesquisa, do Ministério da Saúde e dos Centers for Diases Control and Prevention - CDC (RODRIGUES, 1997).

A dinâmica hospitalar vem atravessando um período de mudanças tão rápidas que dificultam a implementação de projetos arquitetônicos tradicionais, capazes de assegurar os melhores padrões de efetividade, eficácia e eficiência. Durante vários séculos, ergueram-se e instalaram-se nosocômios sem a menor preocupação com sua funcionalidade. Hospitais de pequeno porte, foram se agigantando e geraram verdadeiros labirintos. O pessoal responsável pela funcionalidade da instituição passava a percorrer imensas distâncias e mesmo os projetos verticais, iam assimilando vizinhos e, muitas vezes, a integração não planejada, gerava verdadeiros obstáculos funcionais (CAMPOS, 1997).

Durante longos anos o Governo Federal não manifestou nenhum entusiasmo quanto à regulamentação de projeto e edificações no campo da saúde. Porém, um documento de validade incontestável foi posto em vigor em 1994, a portaria $n^{\circ}$ 1884 do Ministério da Saúde de 11 de Novembro de 1994, publicada no Diário Oficial da União - DOU ausência de vestimenta para los trabajadores, evidenciando la comunicación entre áreas con diferentes niveles de contaminación. Existe predominância de puertas de madera $69,6 \%$ que son contra indicadas por contener agujeros e irregularidades, el $17,4 \%$ de los CME no poseen sumideros en todas lãs áreas y el $34,8 \%$ no poseen sumidores en la depuración. Em el 91,3\% no existen lavabos para lãs manos. El estúdio ha evidenciado el incumplimiento de normas estabelecidas por el Ministerio de la Salud para la estructura física del CME que puede ejercer influencia como dificultadora al procesamiento de artículos en los hospitales que han hecho parte del estúdio y consecuentemente, al control de infección en etas instituciones considerándose ser la esterilización la principal medida de protección anti-infecciosa.

PALABRAS CLAVE: Arquitecture; Esterilización; Infección Hospitalar.

(BRASIL, 1994) em 15 de dezembro de 1995, que regulamenta normas destinadas ao exame e aprovação dos projetos físicos de Estabelecimentos Assistenciais de Saúde a serem observadas em todo o território nacional, nas áreas públicas e privadas, para construções novas, ampliações e/ou reformas (BRASIL, 1994). Essa portaria foi substituída pela Resolução de Diretoria Colegiada $n^{\circ} 50$ de 21 de fevereiro de 2002 (BRASIL, 2002), a qual atualiza as normas existentes na área de infra-estrutura física de saúde e dota também o país de um instrumento norteador das novas construções, reformas e ampliações, instalações e funcionamento de Estabelecimento Assistencial de Saúde que atenda aos princípios de regionaliação, hierarquiação, acessibilidade e qualidade da assistência prestada à população.

Dentro deste complexo contexto do controle de infecção hospitalar e seus fatores determinantes, o Centro de Material e esterilização (CME), ocupa um papel relevante. Este setor destina-se basicamente, a receber e lidar com materiais considerados sujos e contaminados, bem como a preparar roupa limpa reciclada pela lavanderia e ao final do processo, restituí-los esterilizados (BRASIL, 1994).

O planejamento desta unidade é de suma importância, considerando-se as diferentes etapas do processamento dos artigos odonto - médico hospitalares até a sua distribuição às unidades do hospital. Por isso, tal planejamento deve ser executado por uma equipe multiprofissional, cuja atenção deve estar voltada para a dinâmica de funcionamento do setor (SILVA et al, 1997).

Segundo MOLINA (1997) infelizmente, em algumas instituições, o CME é relegado a um segundo plano de importância, não sendo reconhecido o seu valor e relevância dentro da estrutura hospitalar, que é 
GUADAGNIN, Simone Vieria Toledo; PRIMO, Mariusa Gomes Borges; TIPPLE, Anaclara Ferreira Veiga; SOUZA, Adenícia Custódio Silva. CENTRO DE MATERIAL E ESTERILIZAÇÃO: PADRÕES E O PROCESSAMENTO DE ARTIGOS. Revista Eletrônica de Enfermagem, v. 07, n. 03, p. 285 - 293, 2005. Disponível em http://www.fen.ufg.br/Revista/revista7 3/original 05.htm

de assegurar o uso de materiais médico-hospitalares reprocessados e garantir a prevenção das infecções hospitalares.

Hoje, a tendência é que esta unidade, principalmente nos hospitais de grande e médio porte, seja independente e autônoma, com finalidade de apoiar todos os setores que prestam atendimento diagnóstico e terapêutico aos pacientes. Desta forma, garante que todas as etapas do reprocessamento dos artigos (limpeza, secagem, preparo, acondicionamento, desinfecção e/ou esterilização, armazenamento e distribuição) sejam cumpridas, passando por processos padronizados e controlados. Isto implica a utilização dos artigos sem que haja risco ou comprometimento da qualidade do serviço prestado ao paciente, desde o recebimento até a sua distribuição e, ainda, segurança ocupacional (PINTER \& GABRIELLONI, 2000).

O Ministério da Saúde (BRASIL, 1994), em relação à planta física recomenda um fluxo contínuo sem retrocesso e sem cruzamento do material limpo com o contaminado.

Para MUNHÓZ \& SOARES (2000), a maior preocupação deve ser com os materiais de acabamento. A escolha dos mesmos é de fundamental importância, uma vez que alguns detalhes, que a princípio podem parecer indicados, acabam por tornarem-se elementos complicadores para o controle de infecção hospitalar. Esse é o papel fundamental do arquiteto, ele deverá, ao mesmo tempo, preocupar-se com a resistência, com o aspecto visual do ambiente, e com as conseqüências que o material escolhido trará na luta contra as infecções. Vários são os materiais à disposição do projetista, para os revestimentos de paredes e pisos de ambientes de áreas críticas e similares. Os revestimentos devem receber atenção especial nessas áreas. Serão necessárias muitas lavagens nos pisos e paredes. Isso exige materiais que tenham resistência mecânica e à abrasão, suficientes para enfrentar essas limpezas constantes. Devem ser lisos e ter o mínimo de rejuntes entre peças. Os forros devem ser contínuos, para evitar o acúmulo de poeira e a passagem de insetos. As janelas e portas devem constituir-se em superfícies os menos salientes e mais lisas possíveis, que impeçam o acúmulo de poeira e sejam de fácil limpeza.

Segundo o Ministério da Saúde (BRASIL, 1994) os drenos e ralos costumam trazer problemas aos hospitais. Seu transbordamento pode levar agentes patogênicos se aflorarem e contaminarem os pisos alagados. Cabe à arquitetura manutençãopreditiva introduzir técnicas de instalação que previnam essa onipresente ameaça nos projetos de construção de hospitais e outros serviços de saúde.

A experiência vivenciada em $\mathrm{CME}$ e junto às Comissões de Controle de Infecção Hospitalar, nos permitiu observar que os padrões arquitetônicos dos CME são, por vezes, negligenciados. Sabemos que o combate à infecção hospitalar envolve uma ampla gama de aspectos, dentre eles o processamento dos artigos odonto -médico - hospitalares, apresenta-se como importante fator, cuja garantia passa pelo planejamento arquitetônico da área onde o processamento se realiza.

Os objetivos deste estudo foram: identificar os padrões arquitetônicos dos CME dos hospitais de grande e médio porte da cidade de Goiânia e analisar a relação dos padrões arquitetônicos dos CME com o processamento de artigos.

\section{METODOLOGIA}

Estudo realizado em hospitais de grande e médio porte, da cidade de Goiânia. Participaram todas as instituições que constavam da lista obtida junto à Associação dos Hospitais do Estado de Goiás, que se dispuseram livremente, depois de observados os aspectos éticos da pesquisa.

A coleta de dados foi realizada por meio de um check list, contendo questões fechadas sobre os padrões arquitetônicos dos CME, construído a partir do roteiro do Manual para Projetos Arquitetônicos em Estabelecimento de Saúde (BRASIL, 1994).

O check list foi validado por três juizes, com conhecimento e vivência na área, onde foram analisados os aspectos de abrangência, clareza, pertinência, especificidade e ordenação dos itens. Realizamos o estudo piloto em um hospital de pequeno porte do mesmo município.

A coleta de dados foi realizada no período de julho a dezembro de 2000. Os dados foram processados no programa Epi Info 6.04 e analisados utilizando-se de estatística descritiva. Para apresentação e discussão os dados foram agrupados em aspectos arquitetônicos gerais e específicos.

\section{RESULTADOS E DISCUSSÃO}

\section{Padrões Arquitetônicos Gerais}

Em julho de 2000, segundo a Associação dos Hospitais do Estado de Goiás, existiam em Goiânia 26 hospitais classificados como grande e médio porte, desses apenas três não consentiram na realização da pesquisa, 23 instituições participaram do estudo, correspondendo a 88,5\% da população pretendida.

Quanto à localização dos CME, 18 (78,3\%) encontram-se vinculados ao Centro Cirúrgico e cinco $(21,7 \%)$ localizavam-se em andares diferentes.

Verificamos que a maioria das instituições 12 $(52,2 \%)$ possui CME com área física inadequada, proporcionalmente, à quantidade de seus leitos e à complexidade dos serviços oferecidos.

A maioria dos hospitais $15(65,2 \%)$ ainda mantém uma estrutura semicentralizada, incluindo os três hospitais de Goiânia classificados como de grande porte. A centralização de material ocorre em apenas oito (34,8\%) CME. A centralização visa facilitar a operacionalização e a supervisão dos serviços, 
GUADAGNIN, Simone Vieria Toledo; PRIMO, Mariusa Gomes Borges; TIPPLE, Anaclara Ferreira Veiga; SOUZA, Adenícia Custódio Silva. CENTRO DE MATERIAL E ESTERILIZAÇÃO: PADRÕES E O PROCESSAMENTO DE ARTIGOS. Revista Eletrônica de Enfermagem, v. 07, n. 03, p. 285 - 293, 2005. Disponível em http://www.fen.ufg.br/Revista/revista7 3/original 05.htm

como também garantir a qualidade do processamento dos artigos (SILVA et al, 1997; PINTER \& GABRIELLONI, 2000).

O Ministério da Saúde (BRASIL, 1994) estabeleceu parâmetros para a aprovação de projetos físicos de estabelecimentos assistenciais à saúde, onde prevê áreas e dimensões específicas, para cada etapa do processamento dos artigos. Verificamos que 21 (91,3\%) CME não possuem áreas específicas, para cada etapa do processamento dos artigos. O CME é responsável pelo preparo, processamento, estoque e distribuição dos artigos odonto-médico-cirúrgicos necessários para assistência ao paciente. A importância dessa função é clara: se os artigos forem processados inadequadamente será fonte de contaminação e transmissão de microrganismos. Daí a necessidade das áreas de processamento do material ser, fisicamente, separadas e terem espaços apropriados para o desempenho das funções (PEDROSA \& COUTO, 1999). Na prática o que se observa é o descumprimento dessas normas.
Os vestiários são barreiras físicas importantes, na estrutura física do CME, por fazerem a ligação entre áreas críticas e não críticas. Quando o profissional de saúde atravessa de uma área semicrítica para outra crítica, ele deve passar por uma antecâmara (barreira física), que impeça a contaminação de uma área para outra, a contaminação de artigos já esterilizados, mantendo a limpeza do ambiente, reduzindo o risco ocupacional e facilitando o trabalho. (MUNHÓZ \& SOARES, 2000; BRASIL, 1994; SOBECC, 2000). Evidenciamos que a maioria das instituições 21 (91,3\%) é desprovida de antecâmara ou vestiários específicos, para funcionários que trabalham nos CME.

Outra recomendação importante refere-se ao acabamento de portas e janelas que devem ser planejadas no sentido de evitar saliências que possam dificultar a limpeza, bem como não permitir o extravasamento de ar de um ambiente para outro (MUNHÓZ \& SOARES, 2000). A Figura 1 e a Tabela 1 apresentam os tipos de portas e as características das janelas, respectivamente.

Figura 1: Características das portas dos CME, Goiânia, 2001.

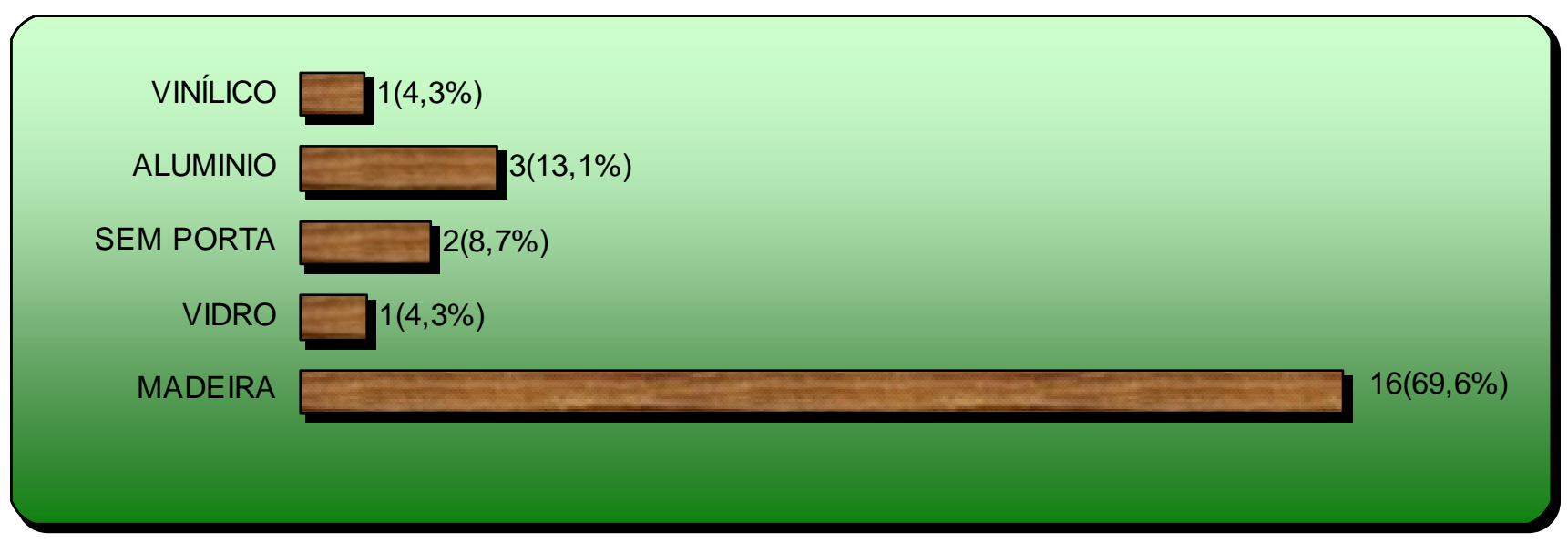

Tabela 1. Distribuição dos hospitais de grande e médio porte, segundo as características das janelas dos CME, Goiânia, 2001.

\begin{tabular}{lcc}
\hline Características das Janelas & Número & $\%$ \\
\hline Amplas com tela & 7 & 30,4 \\
Fechadas / lacradas & 4 & 17,4 \\
Amplas sem tela & 3 & 13,1 \\
Estreitas sem tela & 3 & 13,1 \\
Estreitas com tela & 1 & 4,3 \\
Não possuem janelas & 5 & 21,8
\end{tabular}


GUADAGNIN, Simone Vieria Toledo; PRIMO, Mariusa Gomes Borges; TIPPLE, Anaclara Ferreira Veiga; SOUZA, Adenícia Custódio Silva. CENTRO DE MATERIAL E ESTERILIZAÇÃO: PADRÕES E O PROCESSAMENTO DE ARTIGOS. Revista Eletrônica de Enfermagem, v. 07, n. 03, p. 285 - 293, 2005. Disponível em http://www.fen.ufg.br/Revista/revista7 3/original 05.htm

Chama atenção na Tabela 1 , o fato de seis (26,2\%) CME possuírem janelas sem telas, favorecendo a penetração de insetos, da mesma forma, as portas em 16 (69,6\%) CME são de madeira, contra indicadas por conter frestas e saliências podendo abrigar grande quantidade de poeira, insetos, dificultando a limpeza e aumentando o risco de contaminação dos ambientes (MUNHÓZ \& SOARES, 2000).

Quanto ao revestimento de paredes e pisos, a Figura 2 e Tabela 2 apresentam, respectivamente, os revestimentos utilizados nos $\mathrm{CME}$.

FIGURA 2. Distribuição dos hospitais de grande e médio portes, segundo o revestimento das paredes dos CME. Goiânia, 2001.

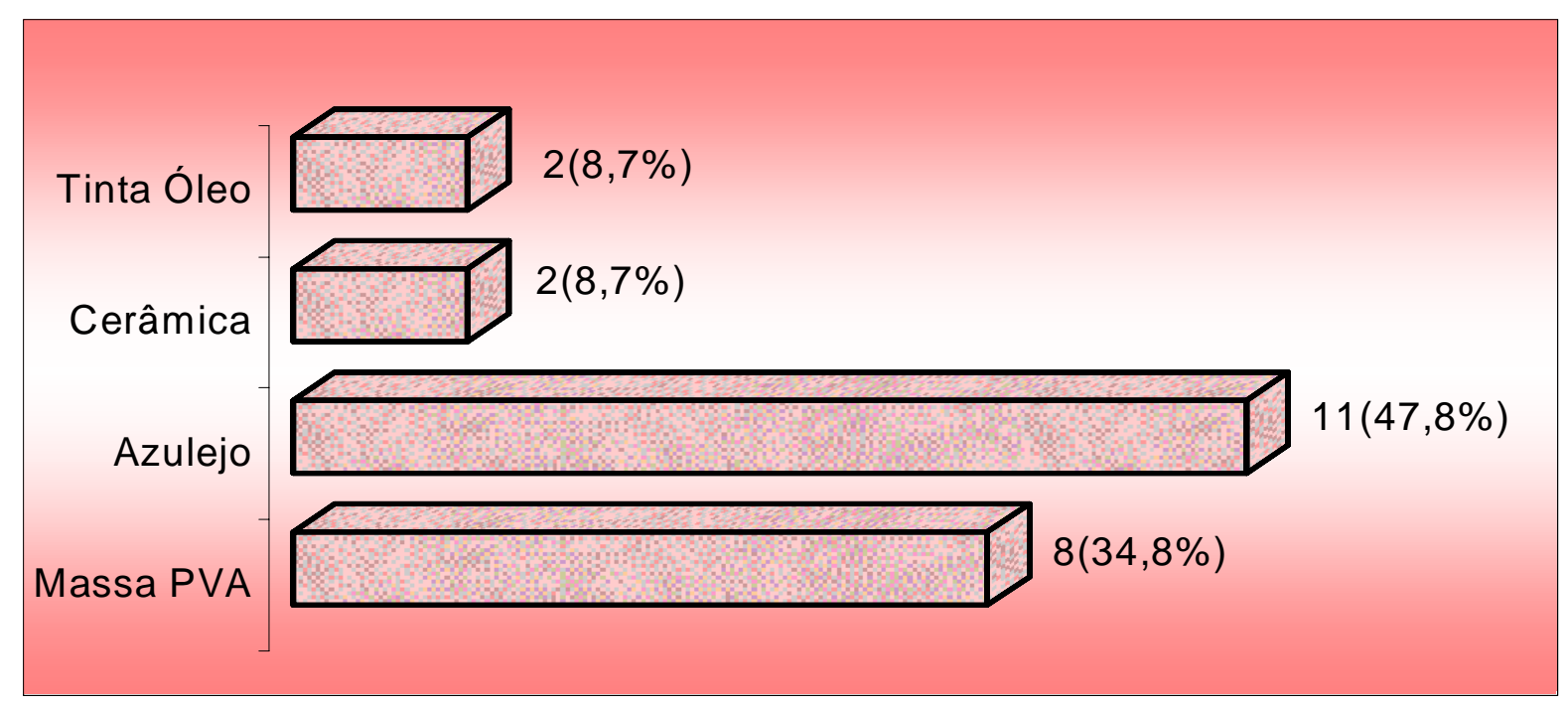

Tabela 2. Distribuição dos hospitais de grande e médio porte, segundo o revestimento do piso dos CME. Goiânia, 2001.

\begin{tabular}{llr}
\hline Revestimento & N $^{\mathbf{2}}$ & \% \\
\hline Granitina & 11 & 47,8 \\
Vinílico & 07 & 30,4 \\
Cerâmica & 05 & 21,8 \\
\hline Total & $\mathbf{2 3}$ & $\mathbf{1 0 0 , 0}$ \\
\hline
\end{tabular}

Vários são os materiais à disposição do projetista, para os revestimentos de paredes e pisos, entretanto devem ser laváveis e resistentes aos desinfetantes (BRASIL, 1994).

$\mathrm{Na}$ Figura 2, predominou o revestimento em azulejo, o qual deve ser evitado em função de sua característica fragmentada $15 \times 15 \mathrm{~cm}$ aproximadamente, o que exige uma excessiva quantidade de juntas de assentamento, inconveniente apontado em produtos dimensionais similares (CAMPOS, 1997).

$\mathrm{Na}$ Tabela 2 observamos que nos $\mathrm{CME}$ predominou 0 piso de granitina 11 (47,8\%), considerado o ideal devido às características que apresenta. Entretanto, cinco (21,8\%) CME ainda possuem o piso de cerâmica, contra-indicado por apresentar grande quantidade de rejunte e ser de menor resistência aos produtos utilizados na limpeza (CAMPOS, 1997).

Os forros das áreas críticas e semicríticas deverão ser contínuos. São contra indicados forros falsos removíveis que podem desprender poeiras e partículas (BRASIL, 1994). A Tabela 3 mostra os tipos de forros dos CME.

Tabela 3. Distribuição dos hospitais de grande e médio porte, segundo o tipo de forro nos CME. Goiânia, 2001.

\begin{tabular}{llr}
\hline Características dos Forros & $\mathbf{N}^{\mathbf{2}}$ & \% \\
\hline Laje & 15 & 65,3 \\
Gesso Acartonado & 06 & 26,1
\end{tabular}


GUADAGNIN, Simone Vieria Toledo; PRIMO, Mariusa Gomes Borges; TIPPLE, Anaclara Ferreira Veiga; SOUZA, Adenícia Custódio Silva. CENTRO DE MATERIAL E ESTERILIZAÇÃO: PADRÕES E O PROCESSAMENTO DE ARTIGOS. Revista Eletrônica de Enfermagem, v. 07, n. 03, p. 285 - 293, 2005. Disponível em http://www.fen.ufg.br/Revista/revista7 3/original 05.htm

Madeira

01

01

Metal Aço

23

O forro é um dos fatores que deve ser levado em consideração, uma vez que eles realizam a vedação do meio externo com o meio interno (BRASIL, 1994). A Tabela 3 mostra que 15 (65,3\%) CME apresentam forros de laje, sendo os mais indicados por serem resistentes e de fácil limpeza. Um (4,3\%) CME possui forro de madeira, contra indicado nesta área, uma vez que a madeira pode conter saliências, frestas, poeiras e servirem ainda de passagem de insetos, dificultando assim a limpeza do ambiente (MUNHÓZ \& SOARES, 2000), seis (26,1\%) possuem forros de gesso que, também, não são recomendados devido a sua fragilidade, podendo conter rachaduras e/ou saliências que dificultam a limpeza (CAMPOS, 1997).

Outro aspecto importante no que se refere aos requisitos de acabamento gerais no CME são os ralos. Drenos e ralos costumam trazer problemas aos hospitais. Os seus transbordamentos facilitam o crescimento microbiano e contaminam os pisos alagados. Cabe à arquitetura: manutenção preditiva, introduzir técnicas de instalação, que previnam essa constante ameaça (BRASIL, 1994). A Tabela 4 apresenta os tipos de ralos dos CME.

Tabela 4. Distribuição dos hospitais de grande e médio porte, segundo o tipo de ralo dos CME. Goiânia, 2001.

\begin{tabular}{llr}
\hline Tipos de Ralos & $\mathbf{N}^{\mathbf{2}}$ & $\mathbf{\%}$ \\
\hline Inox com tampa & 10 & 43,5 \\
Plástico sem tampa & 06 & 26,1 \\
Inox sem tampa & 02 & 8,7 \\
Plástico com tampa & 01 & 4,3 \\
Não possuem ralos & 04 & 17,4 \\
\hline Total & $\mathbf{2 3}$ & $\mathbf{1 0 0 , 0}$ \\
\hline
\end{tabular}

Verificamos que 11 CME possuem ralos com tampa, sendo dez de inox e um de plástico, atendendo às recomendações do Ministério da Saúde. Dois aspectos se destacam na Tabela 4, os CME que não possuem tampas nos ralos e os que não possuem ralos. A inexistência de tampas pode comprometer 0 ambiente, deixando exalar odor fétido nos compartimentos das tubulações, além de propiciar um local ideal para o alojamento de insetos (KARMAN et al, 1997). A inexistência de ralos apresenta-se como um agravo ainda maior, pois o grande desafio para as instalações hidráulicas é de fazer as separações necessárias entre os ramais "normais" e os relacionados às salas de maiores riscos de contaminação. Tubos de esgotos e ralos devem ser separados entre as áreas críticas e não críticas (MUNHÓZ \& SOARES, 2000).

O meio ambiente inanimado, presente em todo o hospital, guarda uma relação com as infecções hospitalares e podem propiciar focos de contato e transmissão por veículo comum, ar, objetos ou vetores. A limpeza constitui um fator de importância prioritária, já que sua execução incorreta acarretará sérios problemas nas sucessivas etapas de outras técnicas higiênico-sanitários (SCARPITTA, 1997). Questionamos como será realizada a limpeza nas áreas que não possuem ralos? A inexistência de ralos e os ralos sem tampas são aspectos dificultadores à execução correta da limpeza nestas áreas contribuindo para a contaminação ambiental.

Outra observação importante diz respeito à lavagem de mãos, considerando a importância das mãos no processo de transferência de agentes potencialmente infecciosos, investigamos a disponibilizarão de recursos para a realização deste procedimento nos CME. Encontramos 21 (91,3\%) CME que não possuem pias destinadas exclusivamente à lavagem das mãos. Dado muito preocupante, uma vez que a lavagem básica das mãos vem sendo considerada, isoladamente, a mais simples, barata e eficaz ação na prevenção das infecções hospitalares (BRASIL,1998). Entretanto vale destacar que a estrutura física tem relação com trabalho nela desenvolvido (estrutura dinâmica) e deve favorecer a prática correta de medida de prevenção e controle de infecção nas instituições de saúde (TIPPLE, 2000).

Outro aspecto dos padrões gerais que verificamos refere-se à inexistência de áreas destinadas ao depósito de material de limpeza (DML) apenas seis $(26,1 \%)$ CME possuem DML. A inexistência desta área implica em guardar materiais de limpeza em outras áreas. Pela necessidade da aproximação do DML com a área de atuação, vimos que o material é acondicionado de maneira imprópria, (no chão, atrás das portas, fundo de escadas e cantos). Levando-se em consideração o volume do trabalho, a freqüência e a diversificação dos produtos utilizados, bem como a necessidade de uso de vários utensílios (rodos, vassouras, desentupidores, etc) e equipamentos para se proceder a limpeza adequada, esta área deverá ter seu espaço reservado no planejamento arquitetônico das instituições de saúde (FIGUEIREDO, 1999).

PADRÕES ARQUITETÔNICOS ESPECÍFICOS 
GUADAGNIN, Simone Vieria Toledo; PRIMO, Mariusa Gomes Borges; TIPPLE, Anaclara Ferreira Veiga; SOUZA, Adenícia Custódio Silva. CENTRO DE MATERIAL E ESTERILIZAÇÃO: PADRÕES E O PROCESSAMENTO DE ARTIGOS. Revista Eletrônica de Enfermagem, v. 07, n. 03, p. 285 - 293, 2005. Disponível em http://www.fen.ufg.br/Revista/revista7 3/original 05.htm

\section{Área de Expurgo}

Segundo PINTER \& GABRIELLONI (2000) um dos objetivos do expurgo é reduzir a carga microbiana dos artigos, tornando-os seguros para manuseio posterior e apto para sofrerem desinfecção/esterilização.

O expurgo deve ser projetado de forma que fique separado das demais áreas do CME pela sua característica de utilidade, as atividades de recepção, separação e limpeza de materiais considerados "sujos" e, portanto, obrigatoriamente, devem ser realizados em ambientes próprios e exclusivos a esta finalidade, assim como o uso de paramentação adequada (BRASIL, 1994). A barreira física serve também, para impedir o fluxo de pessoas da área contaminada para a área limpa (SOBECC, 2000; BRASIL, 1994; MUNHÓZ \& SOARES, 2000).

As barreiras físicas minimizam a entrada de microrganismos externos, o que pode ser realizado por condutas junto a soluções arquitetônicas. São absolutamente necessários nas áreas críticas e semicríticas, e desejáveis nas não críticas (FIGUEIREDO, 1999).

Verificamos que apenas 10 (43,5\%) CME possuem áreas específicas para o expurgo, 13 $(56,5 \%)$ não possuem, sendo que, essas áreas estão associadas a outras, que deveriam estar, também, separadas. A falta de garantia de uma infra-estrutura arquitetônica adequada dificulta a segurança e podem comprometer a qualidade dos artigos processados nos CME que fizeram parte deste estudo.

Quanto às questões relacionadas à troca de ar no ambiente, essas foram vistas em dois aspectos: a existência de janelas e sua forma, e a existência ou não de exaustor. O estudo evidenciou que 21 (91,3\%) CME não possuem exaustores nos expurgos e 10 $(43,5 \%)$ CME não possuem janelas. Dado que chama atenção devido à necessidade de boa aeração neste setor. Quanto à forma das janelas, verificamos que sete $(53,8 \%)$ das existentes são estreitas e não possuem telas.

SIQUEIRA (2000) comenta que é evidente a necessidade de garantir no padrão arquitetônico a existência de exaustor no expurgo, uma vez que se trata de ambiente com risco de contaminação bastante elevado, e ter como agravo para a qualidade do ar a utilização de produtos químicos tóxicos, nesse ambiente. É importante garantir, também, janelas amplas com telas, para ajudar na aeração desse ambiente. A reduzida taxa de renovação do ar põe em risco, tanto a qualidade do processamento dos artigos quanto a própria saúde do trabalhador.

Os ralos são imprescindíveis no expurgo por tratar-se de uma área crítica, com elevado risco de contaminação. O Ministério da Saúde (BRASIL, 1994) preconiza que todas as áreas "molhadas" dos Estabelecimentos Assistenciais de Saúde (EAS) devem possuir ralos com fechos hídricos (sifões). Verificamos que quatro $(17,4 \%)$ expurgos não possuem ralos, dificultando a correta limpeza, também, imprescindível neste setor.

Outro aspecto que chamou a atenção no estudo relacionado à área de expurgo é que a prática de reprocessamento de luvas, apesar de contra indicada, foi evidenciada e $13(56,5 \%)$ instituições, destaca que esse processo é executado no expurgo e em associação a outras áreas.

\section{Área de Preparo de Roupas e Artigos}

O local para o preparo de roupa limpa deve ser separado das demais áreas, porque os tecidos soltam partículas que ficam suspensas no ar (BRASIL, 1994). Encontramos 21 (91,3\%) CME desprovidos de área específica para o preparo de roupa limpa.

Quanto ao preparo de artigos, é uma área que possui especificidades muito bem definidas. É nela que os materiais são separados, conferidos e/ou empacotados, para a esterilização. Observamos que todas as instituições participantes desse estudo apresentam área de preparo de artigos associada às outras áreas do CME.

Acreditamos que esse fator seja de grande agravo para o processamento dos artigos, uma vez que o procedimento de preparo dos artigos realizados em conjunto com outros setores, além de dificultar a operacionalização dos serviços facilita a recontaminação dos artigos, o que pode inviabilizar o processo da esterilização.

\section{Área de Esterilização}

A área destinada para a esterilização dos artigos, também, possui especificidades peculiares e deve ser destinada exclusivamente a este fim (BRASIL, 1994). Observamos que em todos os hospitais pesquisados ela está associada a alguma área física do CME como a de preparo de roupa, de instrumental, armazenamento e de esterilização química.

A esterilização física é um procedimento que vem sendo, gradativamente, ampliado em substituição aos processos químicos, devido aos menores riscos ocupacionais e ao menor custo / benefício, a médio e longo prazos, como menor desgaste do material e maior eficácia (PINTER \& GABRIELLONI, 2000). A associação dessa área pode comprometer a qualidade dos artigos esterilizados.

Em relação à esterilização química líquida, constatamos que apenas duas $(8,7 \%)$ instituições possuem áreas específicas e que a maioria $21(91,3 \%)$ não tem áreas definidas para essa prática. Os materiais que necessitam de esterilização química líquida são processados, dentro dos expurgos, em outras áreas limpas do CME e/ou em salas cirúrgicas. As duas unidades $(8,7 \%)$ que possuem áreas específicas para a esterilização química líquida estão localizadas fora e distante do CME, mas não são unidades autônomas, elas fazem parte do mesmo, 
GUADAGNIN, Simone Vieria Toledo; PRIMO, Mariusa Gomes Borges; TIPPLE, Anaclara Ferreira Veiga; SOUZA, Adenícia Custódio Silva. CENTRO DE MATERIAL E ESTERILIZAÇÃO: PADRÕES E O PROCESSAMENTO DE ARTIGOS. Revista Eletrônica de Enfermagem, v. 07, n. 03, p. 285 - 293, 2005. Disponível em http://www.fen.ufg.br/Revista/revista7 3/original 05.htm

tornando um complicado para controle do processamento dos artigos, tanto para o aspecto operacional, quanto para o risco ocupacional. Ressaltamos ainda que as unidades que possuem esterilização química líquida, os padrões arquitetônicos estão fora das recomendações do Ministério da Saúde (BRASIL, 1994), outros aspectos destacaram-se: em nenhuma das unidades existem exaustores; as janelas são estreitas e sem telas; não possuem lavatórios de mãos e de olhos, não possuem ar comprimido para a secagem do material com lúmen.

A tendência é que os CME, principalmente nos hospitais de grandes e médios portes, sejam autônomos e independentes, garantindo, assim, o controle de todas as etapas do processamento do material, (desde o recebimento até a sua distribuição). Isso implica na utilização dos artigos sem que haja risco ou comprometimento da qualidade dos mesmos (PINTER \& GABRIELLONI, 2000). Para a prevenção das infecções hospitalares deve-se adotar como prioridade 0 trabalho de normatização e acompanhamento dos procedimentos realizados no CME. Para tanto é necessário não apenas conhecer os métodos recomendados de desinfecção e esterilização, mas, também, a dinâmica e o fluxo de trabalho realizado no setor (MOLINA, 1997).

\section{Área de Armazenamento}

Dentre as várias áreas do CME, é conferida ao armazenamento importância relevante devido a sua especificidade, isto é, garantir a qualidade dos artigos já processados até a sua distribuição (BRASIL, 1994). Verificamos que oito $(34,8 \%)$ instituições não possuem áreas específicas para o armazenamento, percentual representativo, uma vez que para ser mantida a esterilidade dos artigos, alguns aspectos devem ser observados em relação ao ambiente, ou seja, deve ser limpo, seco e livre de pó, deve ter área separada, longe da pia ou tubos de drenagem; ter circulação restrita aos funcionários do setor e ter armários fechados ou cestos de fácil limpeza (MOLINA, 1997).

Outro aspecto importante é a climatização desse ambiente. Observamos que apenas duas $(8,7 \%)$ CME possuem ar condicionado na área de armazenamento. A temperatura na área de guarda de artigos estéreis deverá permanecer entre 18 a $22^{\circ} \mathrm{C}$ e a umidade relativa de 35 a 70\% (SOBECC, 2000). Ressaltamos que todos CME estudados possuíam janelas fechadas e lacradas, e naqueles que não tinham ar condicionado a troca de ar e a temperatura do ambiente ficava comprometida. Vale ressaltar que temperaturas e umidades relativas do ar, maiores do que as recomendadas podem promover o crescimento microbiano, já os menores podem afetar certos parâmetros de esterilização (SOBECC, 2000).

\section{CONSIDERAÇÕES FINAIS}

Este estudo mostrou que a maioria dos $\mathrm{CME}$ dos hospitais não atende as normas de projetos físicos para os estabelecimentos de saúde preconizada pelo Ministério da Saúde (BRASIL, 1994).

A maioria dos CME adota, ainda, a prática de semicentralização dos serviços, dificultando a padronização e supervisão das etapas operacionais e consequentemente a garantia da qualidade do processamento dos artigos odonto - médico hospitalares, estes fatores são agravados pela ausência de área específica para cada etapa do processamento dos artigos.

Observamos a importância da arquitetura dos CME no controle das infecções hospitalares, uma vez que podem interferir nas etapas operacionais do processamento dos artigos. Evidencia-se a necessidade da formação de uma equipe multiprofissional para atender, desde as primeiras intenções até o estudo sobre construção ou reforma de um CME.

As normas estabelecidas pelo Ministério da Saúde (BRASIL, 1994) foram atualizadaa pela RDC $n^{\circ}$ 50 (BRASIL, 2002), mesmo o estudo tendo precedido a essa resolução, as alterações sofridas foram no sentido de complementaridade. Assim o cumprimento da resolução constitui uma necessidade primordial a ser cumprida pelas instituições e órgãos competentes das Vigilâncias Sanitária Municipal e Estadual na busca de segurança, para usuários e trabalhadores da saúde.

Da mesma forma consideramos Fundamental o envolvimento dos profissionais que atuam nestes setores, em especial os enfermeiros que assumem a gerencia dos serviços devem comprometer-se com a qualificação do processamento de artigos que tem relação com os aspectos arquitetônicos.

\section{REFERÊNCIAS BIBLIOGRÁFICAS}

BRASIL, Ministério da Saúde. Portaria $n^{\circ} 1884$ de 11 de novembro de 1994. Normas para projetos físicos de estabelecimentos assistenciais de saúde. SAÚDE \& TECNOLOGIA. Brasília, 1994.

BRASIL, Ministério da Saúde: Portaria n²616 de 12 de maio de 1998. Normas para o programa de controle de infecção hospitalar D.O.U., 13 de maio de 1998.

BRASIL, Ministério da saúde: Resolução de Diretoria Colegiada n 50de 21 de fevereiro de 2002. Regulamento Técnico para planejamento, programação, elaboração e avaliação de projetos físicos de estabelecimentos assistenciais de saúde. BRASÍLIA, 2002.

CAMPOS, J. Q. Arquitetura Hospitalar e Legislação. São Paulo: JC, 1997.

FIGUEIREDO, V. M. O. Arquitetura Hospitalar. In: COUTO, R. C., et al. Infecção Hospitalar: epidemiologia e controle. $2^{\mathrm{a}}$ ed. Rio de Janeiro: MEDSI, 1999.

KARMAN, J.; FIORENTINI, D. M. F.; KARMAN, V. H. N. M. A Importância da Arquitetura Hospitalar. In: 
RODRIGUES, E. A. C., et al. Infecções hospitalares: prevenção e controle. São Paulo: Sarvier, 1997.

MOLINA, E. O Centro de Material. In: RODRIGUES, E. A. C., et al. Infecções hospitalares: prevenção e controle. São Paulo: Sarvier, 1997.

MUNHÓZ, M. M.; SOARES, F. Arquitetura Hospitalar. In: FERNANDES A. T. Infecção Hospitalar e suas Interfaces na Área da Saúde. São Paulo: Atheneu, 2000.

PEDROSA, T. M. G.; COUTO, R. C. Central de Material Esterilizado e Processos de Esterilização. In: COUTO, R. C., et al. Infecção Hospitalar: epidemiologia e controle. $2^{\text {a }}$ ed. Rio de Janeiro: MEDSI, 1999.

PINTER, M. G.; GABRIELLONE, M. C. Central de Material e Esterilização. In: FERNANDES, A T. Infecção Hospitalar e suas Interfaces na Área de Saúde. São Paulo: Atheneu, 2000.

RODRIGUES, E. A. C., et al. Infecções Hospitalares: Prevenção e controle. São Paulo: Sarvier, 1997.

SCARPITTA, C. R. M. Limpeza e Desinfecção das Áreas Hospitalares. In: RODRIGUES, E. A. C. Infecções Hospitalares: Prevenção e controle. São Paulo: Savier, 1997.

SILVA, M. A. A.; RODRIGUES, A. L.; CEZARETI, I. U. R. Enfermagem na Unidade de Centro Cirúrgico. $2^{\mathrm{a}}$ ed. São Paulo: EPU, 1997.

SIQUEIRA, L. F. G. Síndrome do Edifício Doente, O Meio Ambiente e a Infecção Hospitalar. In: FERNANDES, A. T. Infecção Hospitalar e suas Interfaces na Área da Saúde. São Paulo: Atheneu, 2000.

SOBECC. Sociedade Brasileira de Enfermeiros em Centro Cirúrgico. Práticas Recomendadas da SOBECC Centro de Material e Esterilização. São Paulo, 2000.

TIPPLE, A. F. V. As interfaces do controle de infecção em uma instituição pública de ensino odontológico. Ribeirão Preto, 2000.177p. Tese (Doutorado) Escola de Enfermagem de Ribeirão Preto, Universidade de São Paulo, Ribeirão Preto.

Texto recebido em 04/10/2005

Publicação aprovada em 10/12/2005 